$\begin{array}{ll} & \text { Etnográfica } \\ \text { etnográfica } & \text { Revista do Centro em Rede de Investigação em }\end{array}$

Antropologia

vol. 25 (1) | 2021

Vol. 25 (1)

\title{
Desafios do "turístico" na atualidade: uma introdução surpreendida por uma pandemia
}

Sofia Sampaio, Frédéric Vidal e Inês Lourenço

\section{OpenEdition}

Journals

Edição electrónica

URL: https://journals.openedition.org/etnografica/9851

DOI: 10.4000/etnografica.9851

ISSN: 2182-2891

\section{Editora}

Centro em Rede de Investigação em Antropologia

\section{Edição impressa}

Paginação: 119-129

ISSN: 0873-6561

\section{Refêrencia eletrónica}

Sofia Sampaio, Frédéric Vidal e Inês Lourenço, «Desafios do "turístico" na atualidade: uma introdução surpreendida por uma pandemia», Etnográfica [Online], vol. 25 (1) | 2021, posto online no dia 05 março 2021, consultado o 30 janeiro 2022. URL: http://journals.openedition.org/etnografica/9851 ; DOI: https://doi.org/10.4000/etnografica.9851

\section{(c) (1) (5)}

Etnográfica is licensed under a Creative Commons Attribution-NonCommercial 4.0 International License. 


\section{Desafios do "turístico" na atualidade: uma introdução surpreendida por uma pandemia}

\section{Sofia Sampaio, Frédéric Vidal e Inês Lourenço}

SAMPAIO, Sofia (sofia.sampaio@ics.ulisboa.pt) - Instituto de Ciências Sociais, Universidade de Lisboa, Portugal.

VIDAL, Frédéric (fvidal@autonoma.pt) - CRIA-ISCTE; Universidade Autónoma de Lisboa, Portugal.

LOURENÇO, Inês (ines.lourenco@iscte-iul.pt) - CRIA-ISCTE, Portugal.

DURANTE MUITOS ANOS, O TURISMO FOI VISTO COMO UM OBJETO DE estudo emergente cuja pertinência e legitimidade científica eram frequentemente questionadas. Antropólogos e sociólogos experimentaram e, em alguns casos, relataram (ex.: Nash 2005) as dificuldades e os desafios próprios de quem se dedica a construir um novo campo de investigação: ausência de financiamento; inexistência de quadros conceptuais e disciplinares adequados; incompreensão por parte dos pares; e, de uma forma geral, uma certa marginalização académica, capaz de gerar, nos seus intervenientes, tanto de entusiasmo quanto de frustração. A perceção do turismo e dos turistas como "intrusos" no trabalho de campo foi dando lugar à vontade de compreender essa presença (M. Silva 1993; Doquet 2010). Foi quando o turismo se afirmou como uma indústria internacional em rápida ascensão, a partir de finais dos anos 60 do século passado, que o interesse das ciências sociais pelo turismo ganhou força e forma. Existe uma bibliografia considerável que procura traçar as origens, expansão e consolidação desse interesse (ex.: Nash 2005; Dann e Parrinello 2009), dando-nos a ver as principais tendências que se estabeleceram desde a criação dos primeiros seminários e cursos (Graburn 1980) até à “explosão" de estudos, em anos mais recentes, muito para lá do âmbito das ciências sociais (cf. Jamal e Robinson 2009) e dos centros geográficos de conhecimento de onde estes estudos começaram por emanar.

Hoje, as abordagens que se dedicam ao estudo do turismo são difíceis de enumerar, tal é a variedade. Com a expansão quer da atividade turística quer dos estudos a ela dedicados, multiplicaram-se e diversificaram-se as vozes de quem investiga e escreve sobre turismo. Continua a ser pertinente a oposição elaborada por Tribe (1997) entre the business of tourism e the non-business aspects of tourism, dois campos de investigação claramente distintos nas suas agendas e 
fóruns de discussão (jornais, redes e associações científicas). A discussão sobre a definição dos estudos turísticos como ciência, disciplina ou campo de estudo nunca deixou de estar completamente fechada. Segundo Darbellay e Stock (2012), o "campo turístico" tem adquirido uma "complexidade específica", nomeadamente devido à heterogeneidade dos atores envolvidos, a dimensão "multilocal" ou "translocal" das relações turísticas, ou a extrema diversidade das suas práticas (cf. Vidal 2010). Nas várias disciplinas das ciências sociais e humanas - as que abordam preferencialmente the non-business aspects of tourism - parece emergir um consenso em torno da ideia de que estudar o turismo nas suas dimensões antropológica, histórica, sociológica ou espacial não deve ser um objetivo em si, mas que o turismo deve ser pensado como uma janela de observação de processos sociais e culturais mais gerais (Spode 2010).

Também em Portugal temos visto um aumento considerável dos estudos sobre o turismo. Não cabe aqui apresentar, mesmo que de uma maneira sintética, a génese e os vários desdobramentos de um campo de estudo tão diversificado. Em geral, e limitando-nos às áreas mais institucionalizadas das ciências sociais e humanas, encontramos a mesma dificuldade ou hesitação na elaboração de uma agenda comum, capaz de refletir a complexidade e a diversidade dos contextos e práticas turísticas. No campo da antropologia, que nos interessa aqui destacar, um momento importante foi a mesa sobre turismo, mobilidades e consumo de lugares promovida pela Associação Portuguesa de Antropologia, em 1999, que esteve na origem de uma coletânea de textos intitulada Outros Trópicos (M. Silva 2004). Na introdução a esta publicação, o turismo é claramente assumido como um "novo terreno", passível de suscitar questionamentos teóricos e metodológicos enquadrados na disciplina, mas abertos a diálogos transdisciplinares (M. Silva 2004: 7). O livro veio inaugurar uma linha de estudos empíricos que entretece o turismo com temas clássicos da antropologia, como a folclorização da cultura popular; a ruralidade; a patrimonialização da cultura edificada, material e imaterial; a identidade nacional; e o encontro etnográfico (ex.: Raposo 2004; L. Silva 2006; Santos 2012; Prista 2013; M. Silva 2015; L. Silva e Leal 2015; Rovisco 2017; Pereiro 2018). Nos últimos anos, as abordagens mais ricas e desafiadoras têm ainda relacionado o turismo com aspetos específicos da transformação das sociedades contemporâneas, tais como o ambiente (ex.: Schmidt et al. 2012; L. Silva e Delicado 2017); os projetos de base comunitária (ex.: L. Silva 2015); a gentrificação, em especial nos centros urbanos históricos (ex.: Baptista, Nofre e Jorge 2018); e a criação cultural e artística. ${ }^{1}$

I Veja-se, por exemplo, o projeto "Creatour: Desenvolver Destinos de Turismo Criativo em Cidades de Pequena Dimensão e Áreas Rurais” (2016-2020), coordenado por Nancy Duxbury. 


\section{DO TURISMO AO “TURÍSTICO”}

Foi, precisamente, face à proliferação e riqueza de trabalhos - que, de certo modo, confirmam o sucesso do turismo enquanto tópico de investigação que organizámos, em outubro de 2017, o colóquio "Desafios do 'Turístico' na Atualidade", de onde resultaram os artigos que fazem parte deste dossiê. ${ }^{2}$ Quinze anos passados sobre a publicação do supracitado Outros Trópicos, pareceu-nos que seria oportuno fazer um balanço sobre o que estava a ser feito e considerar alguns caminhos teóricos mais recentes que, assim nos pareceu, valia a pena explorar.

Ainda antes de o turismo ser reconhecido como um "facto social" que merece ser estudado por si só (Lanfant 2009), já tinha sido sinalizado, nas ciências sociais, como um fator de transformação social (cf. Sampaio, Simoni e Isnart 2014). A preocupação dos impactos, frequentemente negativos, do turismo nos lugares e nas populações rapidamente se afirmou como uma das linhas dominantes da nova área de estudos, ultrapassando os trabalhos iniciais de cariz mais teórico - por exemplo em torno de conceitos como "autenticidade" (MacCannell 1999 [1976]) - e estimulando uma onda de trabalhos empíricos que rapidamente se tornaram clássicos (ex.: De Kadt 1979; Picard 1996). As perspetivas que emanaram da "viragem cultural" (Rojek e Urry 1997), que ganhou terreno nos últimos anos do século XX e inícios do XXI, trouxeram novo fôlego aos estudos de turismo, refletindo, por um lado, o lugar cada vez mais importante do turismo nas sociedades e, por outro, algum cansaço com abordagens que se tinham tornado algo mecânicas e pouco produtivas. O que hoje conhecemos como "estudos de turismo" - uma área de estudos de base interdisciplinar, que cruza áreas como a antropologia, a sociologia, a geografia, a história, a economia, os estudos culturais, os estudos urbanos, entre outras é, em larga medida, resultado dessa "viragem cultural" (cf. Sampaio 2013), que se afirmou contra os excessos de tendências centradas na economia (ou mesmo economicistas) que ignoravam ou empurravam para as margens aspetos do turismo de difícil quantificação ou explicação à luz dos modelos estáveis (e estáticos) que estavam a ser desenvolvidos (cf. Franklin e Crang 2001).

Esta proposta parece-nos continuar válida, ainda que tenha agora de considerar novos fatores, como a diluição da prática turística num conjunto ainda mais vasto e diversificado de lugares, situações e experiências nem sempre identificados como claramente "turísticos". O turismo pode ser considerado como um género "comum" ou "banal" (Lussault 2007), onde a tradicional oposição entre quotidiano e não quotidiano, muitas vezes reificada nas primeiras abordagens sobre o turismo, deixa de operar. É, portanto, também a

2 O colóquio teve lugar no ISCTE-IUL e foi realizado no âmbito do $2 .^{\circ}$ Encontro do Grupo de Investigação Práticas e Políticas da Cultura (GIPPC) do Centro em Rede de Investigação em Antropologia (CRIA). 
dimensão "turística" da vida social que convém questionar. Cardeira da Silva já havia proposto que se devia "preferir o adjetivo (turístico) ao substantivo (turismo)", como forma de evitar processos de reificação (2004: 11). Com efeito, as conceções substancialistas de turismo têm vindo a perder terreno, a favor de abordagens que sublinham o caráter fluido e instável do turístico para adotar o ponto de vista dos atores sociais, das práticas e dos próprios lugares - concebidos como palcos ou locais de encontro e penetração de corpos, subjetividades, espaços, mobilidades, domicílios (dwellings) e performances. Perdem, assim, centralidade as abordagens externas ao turismo, que estudavam os seus "impactos" sobre comunidades locais, para os implicar em estruturas e sistemas normativos abstratos, tais como a modernidade e o capitalismo.

Os atuais entendimentos desenvolvidos a partir de "dentro" arriscam-se, porém, a produzir microanálises que, apesar de descritivamente ricas e historicamente situadas, encontram difícil tradução no debate público sobre a "turistificação" de lugares e práticas, muito centrado em questões como a gentrificação, a patrimonialização, a sustentabilidade, a precarização laboral, ou a conflitualidade entre turistas e locais. Um dos grandes desafios que se colocam - e a que este dossiê pretende, de certo modo, (começar a) responder - é: como produzir um conhecimento sobre o turístico que seja simultaneamente concreto, rigoroso, expressivo, dinâmico e socialmente relevante?

\section{LUGARES DAQUI... E DALI: APRESENTAÇÃO DO DOSSIÊ}

Os seis artigos reunidos neste dossiê constituem bons exemplos de trabalhos que procuraram envolver-se com o caráter fluido e instável do turístico a partir do ponto de vista dos atores sociais, das práticas e dos lugares. Ainda que de diferentes modos, todos eles refletem a proposta de "retomada do lugar", como parte de uma "reterritorialização objetiva da antropologia", no âmbito da qual Cardeira da Silva (2004: 11) pensara a pesquisa do turismo. É a partir da dimensão espacial ou das formas de espacialização - invenção, construção, produção, mediação, mediatização e politização dos lugares e territórios turísticos - que os seis estudos que aqui reunimos se desenvolveram. Em todos eles, o estudo do turístico acontece no contexto de um interesse renovado pelos "terrenos portugueses" (O’Neill e Brito 1991) que justifica retornos e revisitações, mas também no contexto de reconceptualizações sobre esses lugares e "terrenos", que passaram a incluir, de forma eventualmente mais intrincada e acentuada, espaços virtuais, representações, arquivos, registos históricos e memoriais (orais, escritos, audiovisuais), que extravasam o âmbito dos territórios puramente físicos (O’Neill e Brito 1991: 15).

Apresentados no colóquio já mencionado, os estudos de caso empíricos originais reunidos neste dossiê têm um enfoque em contextos predominantemente portugueses (mas não só), permitindo refletir, a partir deles, sobre 
os diferentes usos políticos, culturais, artísticos e ideológicos do turístico nas sociedades contemporâneas. No seu conjunto, articulam uma grande diversidade de perspetivas sobre as múltiplas formas de encontros e interações sociais e culturais observáveis nos lugares turísticos ou transformados, em maior ou menor grau, pela presença de turistas.

Assim, no primeiro artigo, Mariana Silva toma como ponto de observação o "chão de fábrica" de um conjunto de indústrias, localizadas em São João da Madeira, que recentemente abriram as portas a visitas turísticas, no âmbito de um plano de revitalização social e económica da cidade e do concelho. É aí que a autora desenvolve a análise do encontro turístico num contexto fabril em laboração, onde visitantes e trabalhadores confrontam sentidos e ideias distintas de "economia" e "trabalho". Na esteira de estudos semelhantes, a etnografia revela que, mais do que fornecer um "retorno económico direto" (numa espécie de complemento à atividade industrial), a atividade turística, gerida centralmente pelo município, representa uma oportunidade para a localidade renovar a "imagem" com que pretende projetar-se para além do seu território. Esse projeto de "renovação de imagem" passa muito pela "valorização do trabalho industrial e dos seus protagonistas", mas o que a autora encontra, no terreno, é, pelo contrário, a expressão reflexiva de tensões em torno quer do presente vivido quer da perceção de "expetativas para uma vida melhor".

No artigo seguinte, com texto de Ema Pires e desenhos de Mafalda Salgueiro, assistimos à revisitação de uma freguesia rural do Alentejo, Flor da Rosa, que a antropóloga etnografou pela primeira vez entre 1997 e 1999. O regresso ao terreno permite-lhe observar os processos de turistificação e patrimonialização que ali se têm feito, desfeito e refeito ao longo dos últimos 20 anos. O diálogo entre diferentes tempos num mesmo lugar revela a pertinência desta proposta, que conjuga uma revisitação etnográfica "pontual" com uma leitura diacrónica do turístico, para desse modo refletir sobre os processos sociais que se criaram (e continuam a criar-se) em torno das expetativas geradas pelo turismo (ou a seu pretexto). Grande parte do ímpeto analítico do artigo provém do uso interpretativo do desenho e da releitura do diário de campo, dois instrumentos etnográficos cujo potencial merece continuar a ser explorado.

A relevância das diacronias e do nexo história-antropologia para pensar o turismo emerge, de forma clara e convincente, no artigo de Frédéric Vidal, que analisa a produção de um discurso político sobre o turismo, em Portugal, nas primeiras décadas do século XX. O autor recorre aos conceitos de "nebulosa" e "mundo de turismo" para inscrever esse discurso na "constituição de um grupo de atores institucionais e individuais" que, sendo "bastante heterogéneo", não deixava de partilhar noções e objetivos comuns sobre a questão turística. A análise centra-se nos debates, esgrimidos dentro desse "grupo", que buscavam um enquadramento administrativo que fosse "coerente à 
escala nacional e eficiente à escala local". O autor acompanha esses debates (através da imprensa da época, legislação, boletins, relatórios e atas) até ao I Congresso Nacional de Turismo, organizado em Lisboa, em janeiro de 1936. $\mathrm{O}$ artigo é fundamental para se poder ressituar os elementos do discurso em torno do turismo em Portugal - e da sua institucionalização - num quadro mais geral, internacional, onde os aspetos técnicos do setor ocupam um lugar de relevo nas encruzilhadas que, regularmente, opõem iniciativa privada e ação pública aos vários níveis de governação e governança (local, regional e nacional).

No artigo seguinte, Sofia Sampaio coloca igualmente o foco nas práticas e nas técnicas - desta feita desenvolvidas no campo cinematográfico português da década de 1960 - para extirpar os filmes de promoção turística de um modelo único, centralizador, determinista e derivativo de produção de visualidades turísticas (comummente apodado de "olhar turístico"). A autora recorre a entrevistas a profissionais do cinema e seus familiares para, numa espécie de "etnografia retrospetiva", reconstituir os contextos e as práticas de produção de alguns desses filmes. As entrevistas trazem a lume incompatibilidades de fundo entre os campos turístico e cinematográfico (nomeadamente, de pendor estético), mas também revelam entendimentos (geralmente implícitos) sobre o turístico e, portanto, sobre o que deve ou não ser mostrado. Ainda que envolvendo agentes externos ao cinema - os "especialistas da região", os que encomendaram os filmes, eventuais patrocinadores -, realizadores e técnicos assumem a responsabilidade das opções fílmicas que tomaram (que a autora vê como opções práticas, situadas e “incarnadas"), numa lógica interna ao campo de que depende o seu reconhecimento profissional e, não raras vezes, a sua permanência no ofício. Estes resultados não permitem descartar a influência quer da indústria de turismo quer do Estado neste tipo de produção cinematográfica, mas encorajam a realização de análises mais finas, mais atentas aos processos do que a modelos predefinidos (ou aos seus efeitos).

A relação entre o visual e o turístico volta a ser objeto de interesse no artigo de Arlindo Horta. O tema é transversal, de forma mais ou menos direta, mais ou menos desenvolvida, a outros artigos do dossiê - quer Vidal quer Pires assinalam a centralidade da ideia (e dos processos) de embelezamento (que Pires traduz pelo adjetivo "engalanado") em discursos e práticas sobre turismo; enquanto Silva discerne na delimitação de visibilidades e invisibilidades as fronteiras do "visitável". Na esteira de estudos sobre a reterritorialização dos média, Arlindo Horta apresenta-nos uma "etnografia da produção dos média", para analisar a articulação entre a realização de eventos locais (festas de cariz popular) e o programa televisivo nacional Somos Portugal, emitido em direto aos domingos à tarde por uma estação de televisão privada. Ao longo de quase um ano, em 2017, o autor acompanhou a equipa de produção do programa no seu 
périplo semanal por várias localidades, entrando em contacto com uma série de "agentes profissionalizados" distribuídos pelos meios da produção televisiva, da produção de eventos e das autarquias. É entre estes agentes que tem lugar uma intensa negociação do acesso ao espaço mediático, que inclui processos de produção e mercadorização de visibilidade, bem como "performances distintas do visível", de que o autor nos dá conta a partir da análise de um caso particular: a "festa da maçã", em Armamar. Aí, o cotejo de diferentes perspetivas revela uma acentuada convergência de interesses - políticos, televisivos, comerciais, patrimoniais, turísticos - em torno do desejo de "promoção territorial", que tensões episódicas e "desfasamentos" não conseguem anular. Mais do que os participantes e os espetadores habituais, o programa tem por alvo uma "audiência imaginada", na qual se destacam os turistas e a diáspora portuguesa, cuja visita presencial aos lugares emissores é fortemente desejada. Ao turístico cabe, como em tempos pretéritos, a função de "agência de publicidade da nação" (talvez mais do que instrumento do seu desenvolvimento, questão que recebe menos atenção no artigo), com uma diferença essencial: "A nação já não se exalta, consome-se".

A televisualização dos lugares populares "em festa", que Horta discute, no seu artigo, não deixa margem para dúvidas sobre o lugar de destaque que a gastronomia tem vindo a adquirir nos vários contextos do turístico. Disso nos fala Joana Lucas, com base numa etnografia situada em Chefchaouen (Marrocos), que explora a forma como a classificação do património gastronómico (neste caso, a inclusão da dieta mediterrânica na lista de património cultural imaterial da UNESCO) inicia, ou acelera, uma série de transformações e negociações dentro de uma lógica de consumo turístico. A transformação da gastronomia - produtos e práticas alimentares - em património, mas também em mercadoria, configura uma verdadeira "invenção local de uma gastronomia", com efeitos observáveis ao nível da oferta turística que a autora encontrou nos lugares que visitou (nomeadamente, na restauração). O artigo regressa a temas e problemáticas bem conhecidos - as "narrativas patrimoniais" (em especial, as da UNESCO), o papel da comida como "um veículo de consumo do outro", a dieta mediterrânica como um retorno ao mundo rural (ou, pelo menos, às qualidades e aos valores que lhe são frequentemente atribuídos), entre outros. Mas é a análise das formas específicas e concretas que o "empreendedorismo patrimonial" assume em Chefchaouen que permite à autora concluir que a dieta mediterrânica se tem "consubstanciado" mais pelos atores informais e suas práticas (que carateriza como incoerentes e permeáveis a várias influências) do que pelas quatro iniciativas institucionais anunciadas ou em marcha (um museu, um circuito de fornos de pão tradicionais, uma marca que certifica produtos, uma rede de restaurantes comprometidos com produtores locais), que tiveram, até à data do trabalho de campo, fraca implementação. $\mathrm{O}$ artigo vem confirmar o importante contributo da antropologia para o estudo dos 
imbricados laços entre turismo, património e gastronomia, que continuam a crescer em várias direções. Também vem comprovar o potencial crítico e analítico dos lugares - próximos, distantes, vividos, imaginados, frequentemente ligados entre si - como terrenos férteis para a pesquisa do turístico, no sentido em que o temos entendido ao longo desta exposição.

\section{DESAFIOS... INESPERADOS}

$\mathrm{Na}$ introdução ao já citado volume que reúne o testemunho dos primeiros antropólogos e sociólogos que escolheram estudar o turismo, Dennison Nash refere a previsão, pela Organização Mundial de Turismo (UNWTO), de mil milhões e meio de chegadas de turistas internacionais para o ano de 2020 (Nash 2005: 2). Enquanto escrevemos estas linhas, o ano ainda não chegou ao fim, mas os números já revelados ficam muito aquém dessa meta. ${ }^{3} \mathrm{~A}$ inesperada pandemia, causada por uma nova estirpe de coronavírus, que no início do ano desencadeou o cancelamento de viagens, o encerramento de fronteiras e o confinamento de populações, provocou uma paragem nunca antes vista no setor do turismo, em praticamente todo o mundo. Em Lisboa, entre 15 de março (quando o primeiro-ministro declarou o estado de emergência, com restrições a serviços e à movimentação de pessoas) e 4 de maio (quando o desconfinamento foi declarado, ainda que num contexto de estado de calamidade), tuk-tuks e autocarros turísticos abandonaram as ruas. Os aviões deixaram de se ouvir, o habitual fluxo de cruzeiros foi interrompido (ou deixou de permitir desembarques); restaurantes, cafés e lojas de rua permaneceram fechados, em muitos casos mesmo depois do desconfinamento. Com os meses de verão, as praias e os jardins voltaram a ser frequentados, mas bares e discotecas mantiveram-se fechados. Muitos dos principais eventos culturais, como os festivais de música, cuja escala depende da deslocação de públicos internacionais, não tiveram lugar. Abundam, agora, notícias sobre os impactos da falta de turismo na economia. ${ }^{4}$ Não menos importante, no nosso ponto de vista, a abrupta e inesperada ausência de turistas continua a fazer-nos pensar em tudo aquilo que não é necessariamente explicável pela lente da economia (apesar de dela ser inextricável). A pandemia colocou em evidência como o turismo o turístico? - estava, realmente, profundamente intrincado nas nossas vidas, nos quotidianos dos lugares, nos processos sociais, culturais e económicos dos

3 De acordo com os dados do relatório da UNWTO, registou-se uma queda de 65\% no primeiro semestre de 2020: < https:/www.unwto.org/news/international-tourist-numbers-down-65-in-first-halfof-2020-unwto-reports > (última consulta em fevereiro de 2021).

4 A título de exemplo, veja-se < https:/www.publico.pt/2020/09/15/economia/noticia/madeira-lis boa-acores-lideraram-queda-proveitos-turismo-1931635 > (última consulta em fevereiro de 2021) e < https://www.publico.pt/2020/09/04/economia/noticia/turismo-europeu-cai-75-quatro-meses-19303

$7 \mathrm{l}>$ (última consulta em fevereiro de 2021). 
habitantes desses lugares, fixos ou itinerantes. Os atuais discursos sobre as perdas económicas que a interrupção da atividade turística provocou não são de desvalorizar. Mas é importante que não façam esquecer as insuficiências que têm sido apontadas, ao longo dos anos (e, agora, nos textos deste dossiê), a uma visão monolítica e reificadora do turismo como solução única / problema único, no meio de tendências e fenómenos sociais mais vastos, que se fazem sentir, em toda a sua complexidade, nos lugares examinados. Mesmo com os constrangimentos e as incertezas que a pandemia veio trazer quer à prática turística quer à prática investigativa, continua a ser a partir dos lugares que faz sentido continuar a interrogar o turístico.

Numa nota final, gostaríamos de agradecer a Nélia Dias e Sónia Vespeira de Almeida, então coordenadoras do GIPPC do CRIA, pelo convite para organizarmos o 2. ${ }^{\circ}$ Encontro do grupo, bem como a todos os que participaram nesse evento como oradores, debatedores e público. Um agradecimento especial é devido aos autores que nos confiaram os textos que integram este dossiê, respondendo, com empenho, às solicitações, nossas e dos revisores e editores da Etnográfica. ${ }^{5}$ 


\section{BIBLIOGRAFIA}

BAPTISTA, Luís Vicente, Jordi NOFRE, e Maria do Rosário JORGE, 2018, "Mobilidade, cidade e turismo: pistas para analisar as transformações em curso no centro histórico de Lisboa", Sociologia, número temático 8: 14-32.

DANN, Graham M.S., e Giuli Liebman PARRINELlO (orgs.), 2009, The Sociology of Tourism: European Origins and Developments. Bingley, Reino Unido, Emerald.

DARBELLAY, Frédéric, e Mathis STOCK, 2012, "Tourism as complex interdisciplinary research object", Annals of Tourism Research, 39 (1): 441-458, disponível em < https://doi .org/10.1016/j.annals.2011.07.002 > (última consulta em fevereiro de 2021).

DE KADT, Emanuel (org.), 1979, Tourism: Passport to Development? Perspectives on the Social and Cultural Effects of Tourism in Developing Countries. Nova Iorque, Oxford University Press.

DOQUET, Anne, 2010, "La force de l'impact", EspacesTemps.net, disponível em < https://www .espacestemps.net/articles/force-impact/ > (última consulta em fevereiro de 2021).

FRANKLIN, Adrian, e Mike CRANG, 2001, "The trouble with tourism and travel theory?", Tourist Studies, 1 (1): 5-22.

GRABURN, Nelson, 1980, "Teaching the anthropology of tourism", International Social Science Journal, XXXII (1): 56-68.

JAMAL, Tazim, e Mike ROBINSON (orgs.), 2009, The Sage Handbook of Tourism Studies, Los Angeles e Londres, Sage.

LANFANT, Marie Françoise, 2009, "Roots of the sociology of tourism in France", em Graham M.S. Dann e Giuli Liebman Parrinello (orgs.), The Sociology of Tourism: European Origins and Developments. Bingley, Reino Unido, Emerald, 95-129.

LUSSAULT, Michel, 2007, L'homme spatial, la construction sociale de l'espace humain. Paris, Editions du Seuil, disponível em < http://banq.pretnumerique.ca/accueil/isbn/97820210 $08968>$ (última consulta em fevereiro de 2021).

MACCANNELL, Dean, 1999 [1976], The Tourist: A New Theory of the Leisure Class. Berkeley, University of California Press.

NASH, Dennison (org.), 2005, The Study of Tourism: Anthropological and Sociological Beginnings. Bingley, Reino Unido, Emerald.

O’NEILL, Brian, e Joaquim Pais de BRITO, 1991, "Prefácio”, em Brian O’Neill e Joaquim Pais de Brito (orgs.), Lugares de Aqui: Actas do Seminário 'Terrenos Portugueses'. Lisboa, Publicações Dom Quixote, 11-26.

PEREIRO, Xerardo, 2018, "Abordagem exploratória do turismo rural de Trás-os-Montes e Alto Douro (Portugal)”, Análise Social, 226: 58-87.

PICARD, Michel, 1996, Bali: Cultural Tourism and Touristic Culture. Singapura, Archipelago Press.

PRISTA, Marta Lalanda, 2013, “Turismo e sentido de lugar em Óbidos: uma pousada como metáfora”, Etnográfica, 17 (2): 369-392.

RAPOSO, Paulo, 2004, "Do ritual ao espectáculo: 'Caretos', intelectuais, turistas e media”, em Maria Cardeira da Silva (org.), Outros Trópicos: Novos Destinos Turísticos, Novos Terrenos da Antropologia. Lisboa, Livros Horizonte, 137-153.

ROJEK, Chris, e John URRY (orgs.), 1997, Touring Cultures: Transformations of Travel and Theory. Londres e Nova Iorque, Routledge.

ROVISCO, Eduarda, 2017, "Da resistência africanista ao suvenir africano: artesanato, nação e fantasmagoria na ilha da Boa Vista, Cabo Verde”, Etnográfica, 21 (1): 5-26. 
SAMPAIO, Sofia, 2013, "Estudar o turismo hoje: para uma revisão crítica dos estudos de turismo", Etnográfica, 17 (1): 167-182.

SAMPAIO, Sofia, Valerio SIMONI, e Cyril ISNART, 2014, "Tourism and transformation: negotiating metaphors, experiencing change", Journal of Tourism and Cultural Change, 12 (2): 93-101.

SANTOS, Paula Mota, 2012, "The power of knowledge: tourism and the production of heritage in Porto's old city", International Journal of Heritage Studies, 18 (5): 444-458.

SCHMIDT, Luísa, Filipe Duarte SANTOS, Pedro PRISTA, Tiago SARAIVA, e Carla GOMES, 2012, "Alterações climáticas, sociais e políticas em Portugal: processos de governança num litoral em risco", Ambiente \& Sociedade, 15 (1): 23-40.

SILVA, Luís, 2006, “Os impactos do turismo em espaço rural”, Antropologia Portuguesa, 22/23: 295-317.

SILVA, Luís, 2015, "How ecotourism works at the community-level: the case of whale-watching in the Azores", Current Issues in Tourism, 18 (3): 196-211.

SILVA, Luís, e Ana DELICADO, 2017, "Wind farms and rural tourism: a Portuguese case study of residents' and visitors' perceptions and attitudes", Moravian Geographical Reports, 25 (4): 248-256.

SILVA, Luís, e João LEAL, 2015, "Rural tourism and national identity building in contemporary Europe: evidence from Portugal”, Journal of Rural Studies, 38: 109-1 19.

SILVA, Maria Cardeira da, 1993, "Marrocos: turistas, indígenas e antropólogos", Antropologia Portuguesa, 11: 43-49.

SILVA, Maria Cardeira da (org.), 2004, Outros Trópicos: Novos Destinos Turísticos, Novos Terrenos da Antropologia. Lisboa, Livros Horizonte.

SILVA, Maria Cardeira da, 2015, "Old maps, new traffics: political itineraries around scattered heritage of Portuguese origin", em Laurent Bourdeau, Maria Gravari-Barbas e Mike Robinson (orgs.), World Heritage, Tourism and Identity: Inscription and Co-Production. Londres, Ashgate, 227-236.

SPODE, Hasso, 2010, "La recherche historique sur le tourisme: vers une nouvelle approche", Mondes du Tourisme, 2: 4-18, disponível em < https://doi.org/10.4000/tourisme.267> (última consulta em fevereiro de 2021).

TRIBE, John, 1997, “The indiscipline of tourism”, Annals of Tourism Research, 24 (3): 638-657, disponível em < https://doi.org/10.1016/S0160-7383(97)00020-0 > (última consulta em fevereiro de 2021).

VIDAL, Frédéric, 2010, "Faire la ville et pratiquer des lieux: l'histoire du tourisme sur les pas de Michel de Certeau”, Revue d'Histoire des Sciences Humaines, 23 (2): 99-1 15, disponível em < https://doi.org/10.3917/rhsh.023.0099> (última consulta em fevereiro de 2021). 